\title{
Gestão educativa gerencial: superação do modelo burocrático?
}

\author{
Suêldes de Araújo*
}

Alda Maria Duarte Araújo Castro**

\section{Resumo}

0 estudo discute as mudanças ocorridas na gestão pública e suas repercussões no campo educacional a partir da adoção do modelo flexivel de produção. Parte do pressuposto de que as modificações ocorridas nas sociedades contemporâneas foram influenciadas pela necessidade de reorganização do capital que, em crise, tentava superar o modelo taylorista/fordista de produção, por um modelo mais ágil, mais flexivel que atendesse às atuais exigências do mercado. Para a implementação da nova gestão pública, os países latino-americanos passaram a utilizar estratégias que tinham, como referência, o modelo empresarial e se baseavam em critérios de eficiência, de eficácia e de produtividade. Nesse novo paradigma gerencial, defendia a substituição do modelo burocrático de gestão por um modelo descentralizado, com foco no atendimento ao cliente. Essas diretrizes tiveram uma ampla repercussão no campo educacional e foram disseminadas pelos organismos internacionais. Os estudos evidenciam que o modelo de gestão gerencial não têm conseguido superar o modelo de gestão burocrática que existia no interior da escola; o que se constata é a transformação desta em uma burocracia flexivel, coerente com o novo modelo de produção. Palavras-chave: Gestão burocrática. Nova gestão pública. Gestão educacional.

\section{Educational management: overcoming the bureaucratic model? \\ Abstract}

The study discusses the changes in public management and their impacts on the educational field from the adoption of the flexible model production. It is based on the assumption that the changes in

* Mestre em Educação, Professor do Departamento de Educação da Universidade Federal do Rio Grande do Norte. E-mail: sueldesaraujo@yahoo.com.br

** Doutora em Políticas Públicas, Professora Doutora do Programa de Pós-Graduação em Educação da Universidade Federal do Rio Grande do Norte.E-mail: alda@ufrnet.br 
contemporary societies were influenced by the need to reorganize the capital that, in crisis, tried to overcome the Taylor/Ford production model, by implementing a more agile, more flexible one to meet the current demands of the market. For the implementation of the new public management, the Latin American countries started to use strategies based on the business model and the criteria of efficiency, effectiveness and productivity. This new management paradigm advocated replacing the bureaucratic model of management by a decentralized model, with focus on customer service. These guidelines have a broad impact on the educational management and were disseminated by international organizations. Studies show that the management model has been unable to overcome the bureaucratic model of management that existed within the school, which is found in the transformation of a bureaucratic flexibility, consistent with the new model of production.

Keywords: Bureaucratic management. New public management. Educational management.

\section{Gestión educativa gerencial: ¿superación del modelo burocrático? \\ Resumen}

Este estudio discute los cambios ocurridos en la gestión pública y sus repercusiones en el área educacional a partir de la adopción del modelo flexible de producción. Parte de la idea de que las modificaciones ocurridas en las sociedades contemporáneas son fruto de la necesidad de reorganización del capital que, estando en crisis, trataba de superar el modelo taylorista/ fordista de producción, por un modelo más ágil, más flexible que atendiera las actuales exigencias del mercado. Para la implementación de la nueva gestión pública, los países latinoamericanos pasaron a utilizar estrategias que tenían, como referencia, el modelo empresarial y que se basaban en criterios de eficiencia, eficacia y productividad. En ese nuevo paradigma gerencial, se defendía el reemplazo del modelo burocrático de gestión por un modelo descentralizado, con foco en la atención al cliente. Esas directrices tuvieron una amplia repercusión en el campo educacional y se diseminaron por todos los organismos internacionales. Los estudios dejan claro que el modelo de gestión gerencial no ha conseguido superar el modelo de gestión burocrática que existía en el interior de la escuela; lo que si se constata es la transformación de ésta en un proceso de burocracia flexible, coherente con el nuevo modelo de producción.

Palabras clave: Gestión burocrática. Nueva gestión pública. Gestión educacional. 


\section{Introdução}

0 artigo tece uma discussão acerca das mudanças ocorridas na gestão pública e suas repercussões no campo educacional, a partir da adoção do modelo flexivel de produção. Parte do pressuposto de que as grandes modificações ocorridas nas sociedades contemporâneas, no século $\mathrm{XX}$, foram influenciadas pela necessidade de reorganização do capital que, em crise, tentava superar o modelo taylorista/fordista de produção, considerado lento, rígido e padronizado, por um modelo mais ágil, mais flexível que atendesse às atuais exigências do mercado. 0 denominado modelo de acumulação flexivel demanda uma forma de organização descentralizada com participação de todos os envolvidos no processo de produção.

Nesse contexto, a gestão pública, até então burocrática e centralizada, passa a ser influenciada em todos os setores por essas novas idéias, desencadeando alterações substantivas no padrão de regulação e controle dos serviços públicos. Para a implementação dessa nova forma de gerenciamento do setor público, os países passaram a utilizar estratégias de gestão que tinham como referência, o modelo empresarial, e se baseavam em critérios de eficiência, de eficácia e de produtividade.

No campo das políticas sociais, a educação passa a ser entendida como fator de competitividade e estratégia de mobilidade, capaz de possibilitar a inserção dos países em desenvolvimento no mundo globalizado. Para atingir esse objetivo, todo o sistema educacional necessitou ser reformado para se adequar às novas exigências do capital, com destaque para a dimensão da gestão educacional que passou a ser evidenciada como uma estratégia de sustentação da reforma, fundamental para 0 sucesso da aprendizagem e a melhoria da qualidade da educação.

0 presente trabalho está estruturado em três partes. A primeira discute as mudanças no mundo da produção, ocorridas a partir de meados de 1970, e suas repercussões para o modelo burocrático de gestão. A segunda apresenta os novos delineamentos para a gestão pública e as estratégias utilizadas para a sua operacionalização na escola. A terceira analisa o papel dos organismos internacionais na disseminação das novas idéias da gestão educacional na América Latina. Por fim, apresenta algumas considerações sobre os impactos desse novo modelo de gestão no cotidiano das escolas públicas.

\section{Mudanças na produção e as repercussões no modelo burocrático de gestão}

0 homem, no seu dia-a-dia, necessita se organizar para tornar a sua vida produtiva. Em alguns momentos se organiza por uma necessidade individual; em outros, por uma necessidade social. Como necessidade individual, pode-se dizer que a grande maioria pratica um ritual no seu cotidiano, utilizando produtos e serviços que, 
sozinho, não seria capaz de produzir. Todavia, para que essa rotina se concretize na sociedade capitalista, o homem precisa definir onde e como comprar os produtos de que necessita diariamente. Mas, para que esses produtos fiquem disponiveis no mercado, outros homens precisam produzir, organizar e transportar esses produtos objetivando chegar aos estabelecimentos comerciais, tornando-se disponiveis para escolhas, de acordo com a preferência de cada pessoa.

Atualmente, a preferência do consumidor leva em conta o desejo, a quantidade dos produtos na embalagem, a qualidade, a cor, o sabor, além de outros atributos inerentes à escolha, que é diretamente influenciada pela propaganda e pelo marketing. É certo informar que nem sempre foi assim. No princípio da organização do processo de trabalho, não havia ampla liberdade de escolhas porque o modelo de produção artesanal não permitia a produção em larga escala. Com a introdução da máquina no processo de trabalho, $\mathrm{e}$, posteriormente, com o desenvolvimento do sistema taylorista/fordista a produção passou a ser realizada em larga escala; no entanto, na sua maioria, eram produtos padronizados e homogeneizados.

A introdução dos princípios da administração científica - idealizada por Frederick Winslow Taylor ao processo de trabalho - foi um dos marcos do sistema capitalista. Segundo Harvey (1993), as idéias de Taylor se configuraram em um influente tratado, publicado em 1911, que descreve como a produtividade do trabalho pode ser radicalmente aumentada através da decomposição de cada fase do processo de trabalho em seus elementos mais simples, tornando o trabalho fragmentado, segundo padrões rigorosos de tempo e de estudo do movimento. Braverman (1987) informa, com riqueza de detalhes, que a gerência científica parte não do ponto de vista humano, mas do ponto de vista do capital, do ponto de vista da gerência de uma força de trabalho refratária no quadro de relações sociais antagônicas. Para ele, esse modelo de produção:

Não procura descobrir e confrontar a causa dessa condição, mas a aceita como um dado inexorável, uma condição "natural". Investiga não o trabalho em geral, mas a adaptação do trabalho às necessidades do capital. Entra na oficina não como representante da ciência, mas como representante de uma caricatura de gerência nas armadilhas da ciência (BRAVERMAN, 1987, p. 83).

A essas ideias, posteriormente, foi incorporada a linha de montagem de Ford, que possibilitou aumentar a racionalidade do processo de trabalho e permitiu às indústrias da época produzir, em massa, produtos estandartizados. 0 modelo fordista de produção data, simbolicamente, de 1914 quando Henry Ford introduziu seu dia de oito horas de trabalho e cinco dólares, como recompensa para os trabalhadores da linha automática de montagem de carros em Dearbon, Michigan (HARVEY, 1993). Nesse 
modelo de produção a proposta era produzir uma grande quantidade de produtos da mesma forma, com idênticas características para consumo de massa ${ }^{1}$.

Gramsci (apud HARVEY, 1993) em seus Cadernos do Cárcere retrata as implicações sociais desse novo modelo de produção quando enfatiza que o americanismo e o fordismo equivaliam ao maior esforço coletivo para criar, com velocidade sem precedentes, e com uma consciência de propósito sem igual na história, um novo tipo de trabalhador e um novo tipo de homem.

Esse modo de produção, denominado taylorista/fordista, possibilitou a reorganização do capital por muito tempo, tendo chegado a sua época áurea no período do pós-guerra até meados da década de 1970, quando começou a entrar em declínio. Antunes (2000, p. 29-30) afirma que algumas causas contribuíram para motivar a crise do capital, dentre elas:

1- A queda da taxa de lucro, dada, entre outros elementos causais, pelo aumento do preço da força de trabalho; 2pelo esgotamento do padrão de acumulação taylorista/fordista de produção (que na verdade era a expressão fenomênica da crise estrutural do capital), dada pela incapacidade de responder a retração do consumo que se acentuava. Na verdade tratava-se de uma retração em resposta ao desemprego estrutural que então se iniciava; 3 - hipertrofia da esfera financeira, que ganhava relativa autonomia frente aos capitais produtivos; 4- por uma maior concentração de capitais graças às fusões entre as empresas monopolistas e oligopolistas; 5- pela crise do welfare states ou Estado do bem-estar-social e dos seus mecanismos de funcionamento, acarretando a crise fiscal do Estado capitalista e a necessidade de retração dos gastos públicos e sua transferência para o capital privado; 6- incremento acentuado das privatizações, tendência generalizada às desregulamentações e à flexibilização do processo produtivo, dos mercados e da força de trabalho, entre tantos outros elementos contingentes que exprimiam esse novo quadro crítico.

Dessa forma, como estratégia para a superação da crise do capital, o modelo de produção passou a ser questionado. Principalmente, a rigidez da produção e a for-

1 [...] a separação entre gerência, concepção, controle e execução (e tudo o que isso significava em termos de relações sociais hierárquicas e de desabilitação dentro do processo de trabalho) também já estava sendo bem avançada em muitas indústrias. 0 que havia de especial em Ford (e que, em última análise, distingue o fordismo do taylorismo) era a sua visão, seu reconhecimento explícito de que produção em massa significava consumo de massa, um novo sistema de reprodução da força de trabalho, uma nova política de controle e gerência do trabalho, uma nova estética e uma nova psicologia, em suma, um novo tipo de sociedade democrática, racionalizada, modernista e populista (HARVEY, 1993, p. 8). 
ma de organização dos trabalhadores em sindicatos de massa, que negociavam salários uniformes e cresciam em proporção aos aumentos da produtividade, o que corroia as bases do sistema capitalista. À medida que a produção fordista se aproximava de seus limites, surgiram novos métodos de produção. A saturação dos mercados de massa levava a uma crescente diferenciação dos produtos, com uma nova ênfase no estilo e/ou na qualidade.

No entender de Clarke (1991), produtos mais diferenciados exigem turnos de trabalho mais curtos, e, portanto, unidades de produção menores e mais flexiveis. As novas tecnologias, desenvolvidas no pós-guerra e aperfeiçoadas nas últimas décadas, forneceram os meios pelos quais foi possivel realizar, vantajosamente, a produção flexivel,

[...] estas novas formas de produção têm implicações profundas. Uma produção mais flexível requer máquinas mais flexiveis e de finalidades genéricas, e mais operários polivalentes, altamente qualificados, para operá-las. Uma maior qualificação e flexibilidade exige que os operários tenham um grau mais alto de responsabilidade e autonomia (CLARKE, 1991, p. 120).

Essa diversificação da produção capitalista foi uma estratégia encontrada, no final do século XX, para adaptação do sistema a um novo contexto de acumulação de capital com o objetivo de garantir maior lucratividade. Nesse sentido, os interesses de uma força de trabalho mais diferenciada não podem mais ser eficazmente representados por sindicatos e partidos políticos fordistas, monolíticos e burocráticos (CLARKE, 1991). São necessários acordos descentralizados para negociar sistemas de pagamento mais complexos e individualizados, que recompensam a qualificação e a iniciativa. Isso, de certo modo, desmobilizou e enfraqueceu a organização coletiva de trabalhadores.

0 sistema de produção flexível parte, dentre outras, da idéia do desenvolvimento de um padrão de qualidade pela satisfação do cliente. Para isso, utiliza-se o argumento de que é necessário haver um comprometimento com um consumidor cada vez mais exigente, que não demonstra interesse em adquirir um veículo do mesmo modelo, da mesma cor que o do seu vizinho. Atender à satisfação do cliente, aparentemente, parece ser algo normal, principalmente quando a competição e a busca pelos valores são individuais. Nesse sentido, esse fenômeno se apresenta como natural, desconsiderando que a sociedade, em que vivemos, é uma sociedade de classes com interesses antagônicos. A satisfação das pessoas é construída socialmente e, no contexto atual, sofre influências da comunicação ideológica, fruto das idéias neoliberais que estimulam a competição, a individualidade e o egoismo entre as pessoas. 
0 modelo de produção flexível influencia, também, a cultura, determinando uma nova forma de pensar e agir na própria sociedade. Nessa nova lógica, o Estado deve eximir-se da responsabilidade com o financiamento dos setores sociais, como educação e saúde - setores estratégicos para desenvolvimento de uma nação -, transferindo essa responsabilidade para a sociedade civil na forma de privatização dos serviços públicos. Essa contraposição ao modelo de bem-estar-social parte de um discurso paradoxal, segundo o qual o Estado está atendendo a poucos e precisa ser ampliado a todos. Abre-se um debate ideológico de que as pessoas não estão tendo, por exemplo, liberdade de escolher a educação que deseja, porque a opção estatal como única alternativa, cerceia a liberdade dos indivíduos. É necessário ampliar o leque de atendimento, porque a sociedade tem o livre direito de escolhas. $\mathrm{E}$ essas não, necessariamente, precisam ser impostas e financiadas pelo Estado, conforme preleciona Friedman (1985).

A partir do pensamento liberalizante e privatizante de Hayek (1990) e Friedman (1985), a gestão pública burocrática, amplamente centralizada e autoritária, passa a ser questionada como ineficiente por alguns setores da sociedade, provocando novas diretrizes organizacionais. Os defensores dessa nova forma de pensar a gestão pública argumentam que o velho modelo weberiano, classificado como lento e excessivamente apegado a normas, era ineficiente e burocratizado, havendo necessidade de uma participação direta dos cidadãos. Essa tese também é defendida por Bresser Pereira, um dos protagonistas da reforma no Brasil, da década de 1990. Para Bresser Pereira (2003, p. 25):

À medida que a proteção aos direitos públicos passava a ser dominante em todo o mundo, foi-se tornando cada vez mais claro que era preciso refundar a república, que a reforma do Estado ganhava nova prioridade, que a democracia e a administração pública burocrática - as duas instituições criadas para proteger o patrimônio público - precisavam mudar: a democracia devia ser aprimorada para se tornar mais participativa ou mais direta, e a administração pública burocrática devia ser substituída por uma administração pública gerencial.

Essa linha de pensamento tem seus fundamentos em uma política macro-econômica que, no dizer de Abrucio (2003), estaria redefinindo o papel do Estado. Essa redefinição passa pela reorganização das funções do Estado: de um modelo de Estado pautado em políticas Keynesianas², garantindo políticas públicas na área social (edu-

2 A política keynesiana era caracterizada pelo Welfare States - Estado de bem-estar social -, adotado em maior ou menor grau nos países desenvolvidos. Tinha como objetivo primordial a produção de políticas públicas na área social (educação, saúde, previdência social, habitação etc.), para garantir o atendimento das necessidades básicas da população (ABRUCIO, 2003, p. 175). 
cação, saúde, previdência, social, habitação), inspirado no modelo burocrático weberiano, ao qual cabia o papel de manter a impessoalidade, a neutralidade e a racionalidade do aparato governamental, para um Estado fundamentado no modelo de caráter neoliberal, baseado na lógica do mercado, tido como eficiente, ágil, capaz de oferecer serviços de qualidade à população e organizado dentro de um modelo gerencial que privilegia a ótica da eficiência, da eficácia e da produtividade.

Essas ideias podem ser compreendidas como uma disputa de concepção de Estado. De um Estado que acolhe, abriga e dá atenção à população, para um Estado que a deixa à mercê da regulação dos mercados, com a retórica da liberdade fantasiosa.

Na América Latina, mais precisamente, no Brasil, para minar as bases de um Estado acolhedor, uma das deliberações do governo brasileiro, da década de 1990, foi retirar parte das verbas necessárias ao seu funcionamento. Com o Estado oferecendo o mínimo e serviços precários à população, se desvia o debate do aspecto político para o técnico.

Nesse sentido, vai se construindo socialmente a ideia de que o modelo de gestão gerencial, inspirado nas organizações empresariais, é mais ágil e eficiente e, por isso, há grandes chances de apresentar um serviço de maior qualidade. Tenta-se disseminar a ideia de que o setor privado é mais eficiente do que o público.

Nesse cenário de profundas transformações no sistema produtivo, as formas de organização e produção, até então vigentes, sofrem profundas modificações, com repercussões no campo da gestão pública e consequentemente, na gestão educacional, determinando novas diretrizes caracterizadas pela descentralização, pela privatização dos serviços prestados à população.

\section{Gerencialismo: um novo modelo para gestão pública}

As reformas estruturais implementadas no marco do Consenso de Washington (1989) como forma de reestabeceler o crescimento do sistema capitalista e superar a sua crise, na segunda metade dos anos noventa, começam a sinalizar que as promessas de superação da crise em vigor, não se cumpririam em sua plenitude, necessitando, portanto, da criação de um novo programa prescritivo, objetivando reformar o contexto institucional.

Dessa forma, para a superação da crise do sistema capitalista, que se configurava, a partir da década de 1970 e se aprofundava na década de 1980, surgiram medidas para melhoria da qualidade da administração, bem como do sistema judicial e político. Essas reformas visavam a modificar a legislação, a administração pública e a estrutura do governo central para dar maior governabilidade ao Estado. Com o desencadeamento desse processo, a administração pública começava a se 
reformular para além da sua estrutura organizacional, preocupando-se, também, com o desenvolvimento e os resultados das políticas públicas, pautando-se nos exemplos de eficiência, eficácia e produtividade.

Essas iniciativas foram realizadas, inicialmente, com mais intensidade em países do mundo anglo-saxão (Grã-Bretanha, Estados Unidos, Austrália e Nova Zelândia), a partir da década de 1980; depois, gradualmente, na Europa continental no Canadá (ABRUClO, 1997). Esse novo modelo de administração, caracterizado pela busca da eficiência, da qualidade e da produtividade, entre outros, vem configurar a nova gestão pública, que por meio do discurso da ineficiência passa a desqualificar a administração burocrática. Na América Latina, especificamente, no Brasil, as primeiras iniciativas de reforma tiveram início, na década de 1990, e foram orientadas para:

a) a revisão do marco legal (reforma constitucional e da legislação corrente; b) a proposição de uma nova arquitetura organizacional (agências reguladoras, executivas e organizações sociais); c) a adoção de instrumentos gerenciais inovadores (contratos de gestão, programas de inovação e de qualidade na administração pública); e d) a valorização do servidor (nova política de recursos humanos, fortalecimento de carreiras estratégicas, revisão da política de remuneração e intensificação da capacitação de funcionários, visando a promover a mudança cultural) (MARINI, 2003, p. 3-4).

Segundo Bresser Pereira (1998), apesar de a reforma da administração pública ter buscado sua inspiração na administração privada, diferencia-se desta por não visar ao lucro, mas ao interesse público, porque o critério político é nela mais importante do que o critério de eficiência e, também, porque pressupõe procedimentos democráticos que, por definição, não têm espaço no seio de empresas capitalistas.

Ainda segundo Bresser Pereira (1998), a reforma gerencial objetiva aumentar a eficiência e a efetividade dos órgãos e agências do Estado, melhorar a qualidade das decisões estratégicas do governo e sua burocracia e assegurar o caráter democrático da administração pública. Há uma difusão da ideia de que o setor privado é mais eficiente do que o público, portanto, as suas diretrizes de organização devem ser aplicadas ao setor público numa forma de racionalizar os serviços e reduzir o gasto público.

No entender de Bresser Pereira (1998), algumas características permitem uma meIhor compreensão do que seja reforma gerencial, entre elas, podemos destacar: a) a descentralização/desconcentração das atividades centrais para as unidades sub-nacionais; b) a separação dos órgãos formuladores e executores de políticas públicas; c) o controle gerencial das agências autônomas, que passa a ser realizado, levando em con- 
sideração quatro tipos de controles: controle dos resultados, a partir de indicadores de desempenhos estabelecidos nos contratos de gestão; controle contábil de custos; controle por quase-mercados ou competição administrada; e controle social; d) a distinção de dois tipos de unidades descentralizadas ou desconcentradas, as agências que realizam atividades exclusivas do Estado e os serviços sociais e científicos de caráter competitivo; f) a terceirização dos serviços e g) o fortalecimento da alta burocracia.

A defesa é de que as adoções dessas estratégias de gestão ajudarão a racionalização dos serviços, trazendo maior eficiência e produtividade às instituições organizacionais. Em razão disso, Cabral Neto e Castro (2007) ressaltam que, nessa lógica, o setor público precisa se espelhar no setor privado para atingir a qualidade tão desejada por todos. Nesse sentido, a administração de empresas e o seu modelo gerencial tornam-se a inspiração para implementação do novo paradigma de gestão pública na América Latina. A proposta é superar os antigos modelos centralizadores de administração, incorporando a noção de um modelo moderno, caracterizado pela eficiência, pela redução e controle dos gastos públicos, pela demanda de melhor qualidade dos serviços públicos, pela adoção de modelos de avaliação de desempenho, pela proposição de novas formas de controle do orçamento e dos serviços públicos e pela descentralização administrativa.

No campo da educação, o modelo de gestão gerencial, pautado na descentralização administrativa dos macro e micro-sistemas, se apresenta como fórmula prática para resolver os problemas crônicos da educação pública da América Latina. Esse modelo de gestão passa a ser incluído na agenda política como proposta inovadora e modernizadora da gestão educativa dos governos latino-americanos para garantia do sucesso escolar, tendo influência direta nos projetos políticos dos governos da região.

\section{Estratégias gerenciais na educação pública: influências na gestão escolar}

As discussões sobre a utilização de estratégias gerenciais na gestão educacional tiveram início na Grã-Bretanha, em 1986 e, a partir daí, alguns conceitos como o de empowerment (empoderamento) e ao accountability (responsabilização) se difundiram para os Estados Unidos, paises do Leste Europeu, e, em seguida, para os paises em desenvolvimento. Borges (2004) lembra que, nesse ano, os governos da Nova Direita da Grã-Bretanha defenderam a descentralização da gestão educacional em termos de benefício das soluções de mercado para provisão de bens e serviços.

Nesse período, o governo Thatcher, na Grã-Bretanha, buscou tirar proveito do clima de insatisfação criado pela cobertura da mídia, acerca das supostas falhas e excessos cometidos por professores e administradores educacionais, particularmente, no âmbito das autoridades educacionais locais (LEAs), controladas por administra- 
ções trabalhistas. Nesse contexto, a Lei de educação de 1986, reformou os conseIhos locais de administração educacional, de modo a reverter a maioria dos seus representantes, controladas até então por administrações trabalhistas, e ampliou a participação de representantes dos pais e da comunidade de negócios.

Em continuidade à política de reformas da educação da Grã-Bretanha, a Lei de Educação de 1986 impetrou mudanças radicais, transferindo poderes extensivos aos conselhos escolares e aumentou o poder de escolha dos pais e alunos (THOMAS, 1993 apud BORGES, 2004). Para esse autor, as reformas vieram acompanhadas por um movimento de recentralização, na medida em que o governo aumentou seus poderes com o estabelecimento de padrões nacionais de currículo e mecanismos concentrados de avaliação.

Borges (2004) ressalta que, na Grã-Bretanha e no País de Gales, os governos conservadores estimularam a participação de pais provenientes do meio empresarial nos conselhos. Dessa forma, dos quase 75 mil pais-conselheiros das escolas públicas, desses paises, cerca de 20\% provinham do meio de negócios. Levacic (1995 apud BORGES, 2004) ressalta ainda que,

[...] em complemento as estruturas colegiadas de gestão, foram introduzidos elementos de escolha e accountability de mercado. A matrícula livre, isto é, a possibilidade de os pais escolherem a escola de seus filhos independentemente do local de residência, foi combinada com uma fórmula de financiamento baseada no número e na idade dos estudantes, forçando as escolas a competirem pela atração destes.

Esse modelo de administração pública gerencial teve variações em sua aplicação em diversos paises. Na América Latina, em particular, passou a ser calcado sob a lógica de orientações para região, sendo materializado na formulação de políticas com objetivos e estratégias já previamente estabelecidas. Nesse sentido, o processo de reforma desencadeado no continente latino-americano, em consonância com o direcionamento para o setor público, tinha a intenção clara de construir consensos regionais e conceber um projeto homogêneo de educação para todo o continente, no qual o Projeto Principal de Educação (PPE) e o Programa Educação para Todos (EPT) são exemplos. Desse modo,

As reformas educativas desenhadas a partir desse movimento tiveram por base alguns elementos centrais, dentre os quais se destacam: os intensos processos de descentralização; a criação de sistemas nacionais de avaliação de desempenho e de valorização docente; as reformas curriculares; as novas formas de gestão dos sistemas de ensino (CABRAL NETO; RODRIGUEZ, 2007, p. 15). 
De uma forma ou de outra, as orientações para América Latina, repercutiram diretamente nas escolas públicas brasileiras, principalmente na nova forma de conceber a sua gestão que, por meio de estratégias, buscavam garantir um melhor desempenho escolar.

Há um entendimento entre os defensores desse novo modelo, de que, para modernizar a gestão educativa, é necessário superar a gestão burocrática da educação implantando uma gestão mais coerente com o novo modo de produção flexivel, inspirado na liberalização dos mercados. Para isso, torna-se necessário adotar uma série de estratégias que possibilitem a descentralização do sistema público de ensino, com maior participação e controle da sociedade nos serviços prestados. Segundo Castro (2006), essa nova forma de gerenciamento alterou a forma burocrático-piramidal de administração, flexibilizando a gestão, diminuindo os niveis hierárquicos e aumentando a autonomia de decisão dos gestores.

As estratégias para nova gestão pública inauguram através do empoderamento, da responsabilização e da descentralização, um (neo) taylorismo (ABRUCIO, 1997; DE ROSSI, 2004), a partir do momento em que distribui tarefas e delega poder de decisão a em níveis inferiores da escala organizacional. No caso da escola, aos próprios agentes do processo de trabalho, e não somente aos supervisores do tempo e da produtividade, como acontecia no modelo de produção taylorista/fordista. Nessa acepção, as pessoas passam a ser responsáveis diretamente por suas decisões no interior da escola, pelo seu sucesso ou pelo seu fracasso.

Especificamente, no que se refere ao conceito de empoderamento ou empowerment, os estudos são muito recentes, por esse motivo não existe, ainda, uma definição precisa entre os estudiosos da área. No entanto, Borges (2004) enfatiza que o conceito de empoderamento vem associado na literatura à criação de estruturas independentes e autogeridas. No entender de Handler (1996 apud BORGES, 2004), empoderamento é uma disposição psicológica compativel com o autogoverno. Isso significa dizer que o empoderamento nas escolas se dá a partir do momento em que, através das instâncias colegiadas, os cidadãos têm o poder ou a autonomia para planejar, acompanhar, controlar e avaliar, de forma direta, as ações deliberadas, tendo em vista atingir os objetivos estabelecidos pelo coletivo.

Em que pese à defesa por essa nova modalidade de gestão, algumas críticas são bastante pertinentes, principalmente, porque a transferência de algumas responsabilidades não se fez acompanhar de uma destinação de recursos suficientes e de apoio técnico administrativo e pedagógico que permita criar escolas autônomas e efetivas. E esse é o entendimento de Cabral Neto e Castro (2007). Segundo os autores, o novo modelo de gestão se apresenta com (re) significação de vários termos importantes como autonomia, descentralização e participação, na medida em que é subtraído o seu sentido político. 
A autonomia, nesse enfoque, passa a ser entendida como consentimento para construir, na escola, uma cultura de organização de origem empresarial; a descentralização passa a ser caracterizada como desconcentração de responsabilidade e não redistribuição de poder, congruente com a "ordem espontânea" do mercado, respeitadora da liberdade individual e da garantia da eficiência; a participação, por fim, é encarada essencialmente como uma técnica de gestão e, portanto, um fator de coesão de consenso. Não há na instituição escolar, espaço para o conflito, para o debate e para o confronto de ideias (CABRAL NETO; CASTRO, 2007, p. 43).

Diante do exposto, é possível evidenciar que a escola pública vem sendo alvo de uma cultura organizacional nos moldes empresariais que, ao invés de estimular a mobilização política na busca da redistribuição do poder, próprio da gestão democrática, é capaz de obstruir a participação ativa e efetiva de embates e conflitos, por uma legitimada, em que os atores sociais participam, apenas, como coadjuvantes do processo educativo. Na prática, em que pese o discurso da autonomia e da participação, o empoderamento dos grupos desfavorecidos e sub-representados tem sido mais uma exceção do que a regra (BORGES, 2004).

Nessa lógica, as estratégias de empoderamento que acontecem na escola, como exemplo, os Grêmios estudantis, os Conselhos de Classe, os Conselhos escolares, as Assembléias gerais, as eleições para diretores e o planejamento estratégico servem muito mais para legitimar as ações voltadas para implementação da cultura organizacional gerencialista do que para fazer com que as pessoas possam participar, democraticamente, com poderes de decisão sobre os rumos da escola.

No entender de Oliveira (2006), o que há, nesse contexto, é uma tendência de retirar cada vez mais do Estado o seu papel executor e transferir para a sociedade a responsabilidade pela gestão executora dos serviços. Isso é percebido, segundo a autora, na focalização da escola como núcleo da gestão e do planejamento; no financiamento per capita com a criação do FUNDEF; na regularidade e ampliação dos exames nacionais de avaliação; na avaliação institucional e nos mecanismos de gestão escolares que pressupõem o envolvimento da comunidade.

A discussão acerca da estratégia de empoderamento dos atores sociais na escola nos remete a outra estratégia gerencial da nova gestão pública em implantação no país, que pressupõe uma maior responsabilização dos serviços por parte dos gestores. Significa dizer: a utilização de estratégias que possibilite um envolvimento e uma maior participação dos cidadãos na cobrança por serviços de qualidade. Isso nos direciona ao conceito de accountability, que tem sido largamente utilizado nos 
Estados Unidos como forma de garantir aos cidadãos um maior controle dos serviços públicos. Originariamente, o conceito de accountability, segundo Castro (2008), deve ser entendido em um contexto mais amplo de um regime democrático, cujo objetivo é garantir a soberania popular.

0 conceito de accountability (responsabilização) foi utilizado, inicialmente, nas nações anglo-saxônicas, tornando-se central nos Estados Unidos. Em um sentido mais amplo, a ideia era fazer com que os governos tivessem a obrigação de prestar contas à sociedade dos serviços realizados. Campos (1990), tomando como base as idéias de alguns autores, dentre eles, Frederich Mosher, enfatiza que o conceito de accountability, como parte da estratégia gerencial, se traduz em uma responsabilidade objetiva, acarreta a responsabilidade de uma pessoa ou organização perante outra pessoa, fora de si mesma, por alguma coisa ou por algum tipo de desempenho.

Essa estratégia visa a estabelecer uma nova cultura organizacional no interior das escolas, baseadas nos princípios de gestão estratégica e do controle de qualidade, direcionada para a racionalização, eficiência e eficácia dos processos educativos. As diversas formas de accountability são medidas que surgem por meio de reformas nos sistemas de ensino para operacionalizar políticas administrativas de regulação dos sistemas escolares.

Nas escolas, as formas de responsabilização (accountability) estão presentes nos diversos espaços deliberativos. Castro (2008) ressalta que há, nesse contexto, um desvirtuamento do conceito original da accountability, visto que, ao invés de atuar como mecanismo de aproximar os cidadãos dos valores democráticos, de possibilitar o exercício da cidadania plena, é incorporado ao modelo de gestão gerencial, "sendo utilizada numa concepção que enfatiza ganhos de eficiência e efetividade, reduz custos, e aumenta o controle e a fiscalização dos governos sobre as políticas públicas, além de desresponsabilizar o Estado de parte de suas obrigações com os serviços sociais".

A indissociabilidade entre empoderamento e responsabilização deve ser utilizada para caracterizar uma gestão democrática. Para isso, faz-se necessário que os gestores assumam os rumos da democracia e ponham em prática os mecanismos democráticos que facilitem a construção da autonomia no interior da escola, porque a participação tutelada, sob a direção do Estado, não condiz com a democracia. 0 gerencialismo se utiliza dos conselhos de controle social, da gestão participativa e da descentralização, como estratégia, para possibilitar o aumento da capacidade de pais e alunos de intervirem nas políticas internas da escola, reduzindo a interferência de professores e burocratas de suas práticas corporativas, permitindo que a comunidade escolar se responsabilize pelos resultados alcançados. 
Corroborando com essas questões, o Comitê do Centro Latino Americano para o Desenvolvimento (CLAD) (2000), ressalta que a responsabilização através do controle social é uma das formas de accountability mais usadas na atualidade. Campos (1990 apud CASTRO, 2008), discutindo a dificuldade de operacionalizar esse conceito no Brasil, enfatiza que, na nossa cultura política, não há uma tradição de conquistas pela cidadania e que não há compromisso popular com qualquer forma de associativismo. Para a autora, em lugar de participar de organizações que congreguem os seus próprios interesses, ou para enfrentamento do poder do Estado, as pessoas preferem esperar que o Estado defenda e proteja os interesses não organizados, dificultando a operacionalização de uma participação mais efetiva do cidadão para reivindicar os seus direitos.

Ressaltamos que, além da falta de uma cultura de participação, outros fatores podem contribuir para que essa participação não se efetive na prática, dentre eles, destacamos: as diversas estratégias que o Estado utiliza para defender os seus interesses, como por exemplo, a forma como são indicados os conselheiros que atuam nos diversos conselhos em funcionamento no país. Apesar de a legislação indicar que eles devem ser escolhidos pelo voto, na prática isso não se efetiva na sua totalidade. Essa prática se reflete nas escolas, pois a grande maioria dos conselheiros acaba sendo indicada ou convidada pelos gestores em exercício.

A ampliação da participação coletiva de forma qualificada nos colegiados pode ser entendida como uma estratégia capaz de superar a administração autoritária até então vigente na escola. Contudo, sabe-se que essa qualificação da comunidade escolar não acontecerá ao acaso ou pelas vias do Estado; ela ocorrerá a partir de um compromisso político dos que fazem a gestão por meio de um processo sistematizado de formação política para que o coletivo da escola chegue a um nivel de consciência que supere, naturalmente, qualquer gestão autoritária. Nesse sentido, a tomada de decisão com relação à responsabilização, partirá da tomada de consciência, contribuindo para se alcançar os fins a que se destina a educação numa perspectiva democrática. Esse é um desafio posto aos gestores comprometidos com uma educação de qualidade socialmente referenciada.

A modernização da gestão escolar vem sendo uma temática recorrente em todo o continente latino-americano. Para isso, contou com a colaboração dos organismos internacionais, que, por meio de encontros sistematizados e de elaboração de diretrizes e documentos procuram disseminar a ideia de que 0 sucesso da escola depende da forma como ela é gerenciada e que, sem modernização da gestão e o uso de estratégias gerenciais, dificilmente conseguiremos atingir uma educação de qualidade. 


\section{De Jomtien a Dakar: as diretrizes internacionais para gestão educacional na América Latina}

A modernização da gestão e o surgimento de novas estratégias no campo gerencial desencadearam um processo de discussão em toda a América Latina na década de 1990 tendo, como referência, a Conferência Mundial sobre Educação para Todos $^{3}$. Os estudiosos mostram que, durante uma década (1990 a 2000), houve avanços e retrocessos nas negociações a respeito de um novo modelo de gestão que viesse superar os problemas educacionais, melhorar os índices de aprendizagem das escolas e ainda, propiciar a melhoria da qualidade da educação.

Desde o documento resultante da Conferência de Jomtien (DECLARAÇÃO..., 1990), que já se apontava para a necessidade da ampliação dos direitos à educação no âmbito mundial e o estabelecimento de metas decenais, visando à educação para todos e todas. Entre os seus objetivos, podemos evidenciar: a satisfação das necessidades básicas de aprendizagem de cada pessoa - criança, jovem ou adulto; a ampliação dos meios e do raio de ação da educação básica, propiciando um ambiente adequado à aprendizagem e ao fortalecimento de alianças; o desenvolvimento de uma política contextualizada de apoio; a mobilização de atuais e novos recursos financeiros e humanos, públicos, privados ou voluntários; o fortalecimento da solidariedade internacional.

Entendemos que a satisfação das necessidades básicas de aprendizagens apresentadas na Declaração de Jomtien se constitui em um paradoxo, visto que não diz respeito à ampliação dos direitos à educação no âmbito mundial, mas ao conhecimento de habilidades, atitudes e valores necessários para as pessoas sobreviverem na informalidade em tempos de desemprego estrutural. Por outro lado, ressaltamos que incluir a educação como eixo central para o desenvolvimento econômico torna-se uma opção ilusória para a classe trabalhadora, tendo em vista que o mercado de trabalho não consegue absorver todos os trabalhadores disponiveis por conta do desemprego estrutural. Entretanto, a eficácia da educação como meio de obtenção do desenvolvimento econômico, e como mecanismo de equalização social, pode ser observada com muita clareza nos documentos oficiais para a educação em âmbito nacional e internacional (OLIVEIRA, 2005).

Em análise aos artigos da Declaração de Jomtien (DECLARAÇÃO..., 1990), é possivel estabelecer uma articulação com os pressupostos neoliberais. Nesse sentido, ressaltamos os art. 7 e art. 8, pois se referem à redução do papel do Estado na educação e à redução do financiamento da educação pública, estimulando a parti-

3 Convocada pelo Banco Mundial, pela UNESCO (Organização das Nações Unidas para Educação, Ciência e Cultura) e pelo UNICEF (Fundo das Nações Unidas para a Infância), a Conferência de Jomtien tomou como referência o documento elaborado pela Comissão Econômica para a América Latina, Transformación productiva com eqüidad - 1990, que apresentava a educação como elemento central para o desenvolvimento dos países e para a sua inserção no mundo globalizado 
cipação da sociedade civil ao estabelecimento de alianças e parcerias para conseguir atingir a meta de educação básica para todos.

Esses artigos retratam, claramente, a orientação para que se estabeleça um pacto ou aliança do Estado com toda a sociedade civil para a efetivação da educação básica. Essa diretriz apresenta repercussões diretas no papel que o estado tem mantido até então, de financiador da educação pública, reduzindo as suas responsabilidades com o financiamento, com a organização e com a avaliação da educação básica. É uma diretriz que induz à privatização dos serviços educacionais, de duas formas: a primeira, em que a sociedade assume indiretamente os custos com a educação, e a segunda, por meio da descentralização dos recursos públicos para administração da iniciativa privada por meio de subvenções ou vouchers, como ocorreu no Chile.

A repercussão dessas orientações é percebida no cotidiano das escolas. A descentralização dos recursos financeiros, a autonomia para a organização e o apelo à participação da comunidade escolar e local na gestão da escola já se fazem bem presentes nas unidades escolares brasileiras. As campanhas para voluntariado, como exemplo $O$ Programa Amigos da Escola, cuja intenção daqueles que querem participar é louvável, mas apenas, legitimam as políticas neoliberais e contribuem com o projeto de desresponsabilização do Estado com a educação pública.

No Art. 10 (DECLARAÇÃO..., 1990) está o fechamento da proposta educacional para a América Latina. Fortalecer a solidariedade internacional. 0 artigo aponta para a necessidade de uma rede de solidariedade entre os países, no sentido de buscar resgatar as dividas sociais, principalmente junto aos paises mais pobres que mantêm um déficit educacional muito alto com a população. Nesse sentido, percebemos que há, nesse artigo, uma articulação com as propostas mais progressistas da UNESCO, que entende solidariedade como um conceito no qual se deve enxergar e se interessar pelos outros, fazendo-se algo por eles. No entanto, verifica-se que essas ajudas, quando efetuadas, principalmente no campo das assessorias e do financiamento, estão sempre associadas a um retorno em termos de juros dos recursos utilizados, principalmente, quando os grandes financiadores são os bancos.

Para a implementação das novas diretrizes propostas na Conferência de Jomtien, e os novos delineamentos da política educacional para a região, é importante ressaltar o papel do Projeto Principal de Educação na América Latina e Caribe (PPE). Esse Projeto tinha como objetivo a construção conjunta de uma política educacional de longo prazo para a região, que tivesse impacto nas políticas de desenvolvimento (UNESCO, 2001). A proposta central do projeto é regida por um conjunto de princípios que associam a educação com o desenvolvimento das nações, com sua independência política e econômica, com a qualidade de vida das pessoas e o desenvolvimento de potencialidades do ser humano. 0 PPE nasceu com o objetivo de 
elaborar, acompanhar e avaliar as ações implantadas na região no campo educacional. Depois de sua fundação seguiram-se reuniões, em Santa Lúcia (1982), no México (1984),e em Bogotá (1987).

A partir da década de 1990, logo após a Conferência Mundial sobre Educação para Todos, em Jomtien, na Tailândia, o Comitê Regional Intergovernamental do Projeto Principal de Educação redireciona seus objetivos à Declaração Mundial sobre Educação para Todos, caracterizando-a como Marco de Ação (2000) para satisfação das necessidades básicas de aprendizagens na América Latina. Esse é um dos pontos de inflexão do PPE, pois, a partir da Conferência, toda a ação do Projeto é redimensionada.

Como forma de orientar os Estados Membros acerca das diretrizes para implementação das reformas educacionais na região, outros vários encontros do Comitê Regional Intergovernamental (PROMEDLACS) aconteceram no âmbito do PPE, originando declarações relativas à execução de planos nacionais de ação.

A reunião do Comitê Regional Intergovernamental, realizada em Quito (1991), foi considerada importante, pois, a partir dai, o PPE é reestruturado e suas ações passam a incorporar as decisões de Jomtien, principalmente no que se refere ao desenvolvimento de um novo modelo educativo ligado à transformação produtiva com equidade. A Declaração de Quito enfatiza, ainda, que a educação deve ser objeto de grandes consensos nacionais que garantam o compromisso de toda a sociedade para formação de suas futuras gerações e a continuidade de políticas e programas postos em marcha para atender a esses objetivos.

No que se refere à gestão educacional, a Declaração ressalta que, para responder às exigências globais, é necessário produzir uma transformação profunda na gestão educativa tradicional, permitindo articular efetivamente a educação com as demandas econômicas, sociais, politicas e culturais, rompendo com o isolamento das ações educativas, transformando sua contribuição em uma efetiva força para 0 desenvolvimento econômico, e na justa distribuição de riqueza com a participação cidadã. Defende, ainda, a necessidade de criar e desenvolver mecanismos e estratégias de alianças entre diferentes setores da administração pública, entre os organismos governamentais, empresas privadas, os veículos de comunicação, as igrejas, as entidades comunitárias e as próprias famílias.

0 pacto social proposto pela Declaração é uma orientação para distribuição de responsabilidades entre Estado e sociedade civil. Essa proposta tem ligação direta com os setores produtivos, tendo em vista que, quanto mais a sociedade civil assume a responsabilidade pelos serviços educacionais, maior a possibilidade de 0 Estado diminuir os tributos a esses setores, gerando uma possibilidade real de maior acumulação de capital. 
0 documento aponta, ainda, para a modificação significativa dos estilos de planejamento e administração. Segundo a Declaração de Quito (1991), a administração dos sistemas educativos não assegura a participação plena dos principais atores do processo pedagógico; não se responsabiliza pelos baixos resultados do sistema; não focaliza as ações nos setores prioritários da população; e não promove a inovação e a criatividade dos docentes. Por isso, precisa ser modificada. Dessa forma, indica a necessidade de impulsionar processos de descentralização, regionalização e desconcentração, projetando ágeis mecanismos de avaliação de resultados, de implementação de programas eficazes de compensação educativa, de impulsionar programas de emergência apelando para mecanismos extraordinários visando a resolver situações críticas que afetam as populações em condições de pobreza e marginalizadas. A nova estratégia de gestão trará, segundo esse documento, uma melhoria da qualidade da educação.

Em 1993, a UNESCO convoca para uma reunião em Santiago do Chile, os Ministros de Educação e chefes de delegação da América Latina e Caribe, quando é elaborada a Declaração de Santiago (UNESCO, 2001). Nessa Declaração, fica explícito que os Ministros da região reconhecem os esforços e êxitos conseguidos, mas que é necessário iniciar uma nova etapa de desenvolvimento educativo. Reiteram que a educação é responsabilidade de todos e não só do Estado, de um setor e de um grupo; ratificam a distribuição de responsabilidades pela educação entre Estado e sociedade civil; e a necessidade de modernizar a gestão.

No campo da gestão educacional, há o reconhecimento de que existe a necessidade de profissionalizar as ações dos ministérios de educação, dotando-os de recursos adequados e modernos, definindo competências específicas e novas capacidades humanas, políticas, sociais e técnicas, tanto nos níveis centrais, como nos níveis regionais e locais. Dessa forma, há o reconhecimento de que é preciso profissionalizar a gestão da escola, dando aos estabelecimentos maiores atribuições para regular e fortalecer as capacidades dos docentes, a fim de que estes possam levar adiante o processo educativo com todas as condições de uma atividade profissional, devendo ser capaz de tomar decisões e de estar disposto a assumir responsabilidades pelos resultados.

Merece destaque, também, a sexta reunião do Comitê Regional Intergovernamental - PROMEDLAC VI, em 1996, realizada na cidade de Kingston, na Jamaica. 0 documento-base apresentado, nessa reunião reafirma os compromissos assumidos pelos governos da região quando foi criado o PPE. Reivindica uma educação permanente e propõe como metas a universalização da educação básica e a alfabetização funcional, assim como a promoção dos chamados quatro pilares da educação, contidos no relatório da Comissão Internacional sobre a Educação para o século XXI da UNESCO (2001): aprender a aprender, aprender a ser, aprender a fazer e aprender a conviver. 
Nesse sentido, os integrantes da reunião se comprometeram a seguir, entre outras, as seguintes orientações para formulação e execução de políticas educativas nacionais para região: a educação como política de Estado; melhorar a capacidade de gestão com maior protagonismo da comunidade educativa local e um papel mais estratégico da administração central; qualidade para assumir responsabilidade pelos resultados da educação; valorização profissional dos docentes ligada ao desempenho; a educação ao longo de toda a vida para uma aprendizagem contínua; a educação superior como fator crítico para o desenvolvimento da região; financiamento e alocação de recursos.

As recomendações de Kingston, em 1996 (UNESCO, 2001), se aproximaram da proposta da nova gestão pública que estava em processo de discussão na América Latina, na medida em que se exploraram as temáticas do empoderamento e da responsabilização, levando uma proposta de gestão com protagonismo da comunidade educativa local. Apontou, também, para valorização dos docentes por meio da meritocracia, e da produtividade da educação por meio da avaliação, mensuração, e responsabilidade pelos resultados, dentre outras temáticas que se vincularam diretamente a essa proposta.

Nesse sentido, a declaração de Kingston (UNESCO, 2001) promete melhorar a qualidade da educação pública e elevar o acesso ao conhecimento, a cultura, a cidadania a todos: crianças, jovens e adultos; valorizar e qualificar o profissional da educação; fortalecer o papel da escola e efetuar trocas dos modelos pedagógicos e de gestão educativa; racionalizar os recursos financeiros; e diminuir a pobreza através da educação.

Considerando as análises apresentadas, podemos destacar que as recomendações oriundas dos PROMEDLACS, na sua maioria, tornaram-se hegemônicas na América Latina e foram implementadas de forma diferenciada nos diversos paises a depender das resistências internas. Após dez anos da Conferência de Jomtien, na qual os paises viveram um contexto de restrições de financiamento, a Cúpula Mundial de Educação ${ }^{4}$ se reuniu em Dakar, no Senegal, de 26 a 28 de abril de 2000, com o propósito de

4 Os representantes dos 180 países presentes à Cúpula Mundial de Educação, em Dakar (Senegal), entre 26 e 28 de abril de 2000, tiveram o amargo sabor de admitir que não fizeram a lição de casa, proposta em 1990 na Conferência Mundial de Educação para Todos, em Jomtien (Tailândia). Os 155 governos signatários da Declaração de Jomtiem se comprometeram a colocar toda criança na escola até o ano 2000, porém ainda hoje, 125 milhões de crianças nunca estiveram numa sala de aula, sendo que 2/ 3 são meninas, sem falar nos $\mathbf{8 8 0}$ milhões de adultos analfabetos. Outro compromisso descumprido foi que a assistência financeira para a educação básica seria elevada. Apenas na África, a ajuda financeira despencou 3 bilhões de dólares, de 1990 para cá. A garantia de que os programas do Fundo Monetário Internacional estariam alinhados aos compromissos com a educação também foram jogados por terra, quando o próprio FMI admite que pelo menos 12 países da África reduziram seus gastos com educação, sob o impacto de programas do Fundo. Outra promessa vazia foi que o Banco Mundial colocaria em prática seus programas de Educação para Todos. A instituição, que ampliou seus empréstimos para o setor é hoje o principal fundo para a educação, continua responsabilizando apenas os pais pela educação dos filhos (HADDAD; SILVA, 2000). 
traçar um Marco de Ação, comprometendo-se a alcançar os objetivos e as metas de Educação para Todos (EPT): para cada cidadão e cada sociedade. Os governos, conforme o documento, têm a obrigação de assegurar que os objetivos e as metas de EPT sejam alcançados e mantidos. Segundo a Declaração de Dakar (MARC0..., 2000), essa responsabilidade será atingida de forma mais eficaz através de amplas parcerias no âmbito de cada país, apoiada pela cooperação com agências e instituições regionais e internacionais, ratificando, também, as declarações da década analisada.

0 documento elaborado em Dakar (MARCO..., 2000) reafirma a visão da Declaração Mundial de Educação para Todos em Jomtien (DECLARAÇÃO..., 1990). Apoiada pela Declaração Universal dos Direitos Humanos (2009) e pela Convenção sobre os Direitos da Criança (2009), de que toda criança, jovem e adulto tem o direito humano de beneficiar-se de uma educação que satisfaça suas necessidades básicas de aprendizagem, que incluam aprender a aprender, a fazer, a conviver e a ser, proposto pelo relatório da Comissão Internacional sobre a Educação para o século XXI (UNESCO, 2001).

O Marco de Ação de Dakar (MARCO..., 2000) propõe seis objetivos para garantia das necessidades básicas de aprendizagem: a) expandir e melhorar o cuidado e a educação da criança pequena, especialmente para as crianças mais vulneráveis e desfavorecidas; b) assegurar que todas as crianças, com ênfase especial nas meninas e crianças em circunstâncias dificeis, assim como as que pertencem a minorias étnicas, tenham acesso ao ensino fundamental gratuito e obrigatório de boa qualidade até o ano de 2015; c) assegurar que as necessidades de aprendizagens de todos os jovens e adultos sejam atendidas mediante um acesso equitativo à aprendizagem apropriada, a habilidades para a vida a programas de formação para cidadania; d) alcançar uma melhoria de 50\% nos niveis de alfabetização até 2015, especialmente para as mulheres, e acesso equitativo à educação básica, e continuada para todos os adultos; e) eliminar disparidades de gêneros na educação primária e secundária até 2005 , e alcançar a igualdade de gênero na educação até 2015, com enfoque na garantia ao acesso e desempenho pleno e equitativo de meninas na educação básica de boa qualidade; e f) melhorar todos os aspectos qualitativos da educação e assegurar excelência para todos, de forma a garantir a todos resultados reconhecidos e mensuráveis, especialmente na alfabetização, na matemática e nas habilidades essenciais à vida (MARCO..., 2000).

Para atingir esses objetivos, a Cúpula Mundial de Educação compromete-se, entre outros, a: desenvolver sistemas de administração e de gestão educacional que sejam participativos e capazes de dar resposta e de prestar contas; assegurar o engajamento e a participação da sociedade na formulação, implementação e monitoramento de estratégias para o desenvolvimento da educação.

Identifica-se na Declaração de Dakar (MARCO..., 2000) um forte compromisso de levar adiante a intenção de aplicar o modelo gerencial para educação, enfatizan- 
do que o desafio, agora, é cumprir os compromissos firmados. A gestão educacional nessa perspectiva, deve ser realizada por meio do planejamento estratégico o qual surge como fórmula para racionalizar os parcos recursos financeiros, à imagem e à semelhança da empresa privada. Esse modelo foi sendo adotado, gradativamente, em todos os paises da América Latina.

Estudos realizados por Gajardo (1999) e Fonseca e outros (2004) registram que todos os paises da região, em maior ou menor escala, promoveram reformas nos seus sistemas educacionais para atender às diretrizes postas a partir da Conferência de Jomtien (DECLARAÇÃO..., 1990). No entanto, chegamos ao século XXI com muitas metas e objetivos que não foram atingidos em sua plenitude e com um grande déficit educacional tanto quantitativo quanto qualitativo. Isso significa que os governos dos paises emergentes, apesar de sofreram uma forte influência dessas organizações - quer seja por motivos econômicos, políticos, sociais ou culturais - não conseguiram atingir os objetivos previstos para a educação no mundo globalizado. Constata-se, ainda, que há uma persistência em atingir os objetivos de Jomtien, demarcando que continua presente a crença da correlação entre o binômio educação e desenvolvimento e que é através da educação que os países em desenvolvimento poderão se inserir no mundo globalizado.

\section{Considerações finais}

0 estudo evidenciou que o modelo de produção flexivel e a adoção dos ideais neoliberais têm forçado o Estado a desresponsabilizar-se de parte do financiamento de setores essenciais para o funcionamento da sociedade, incluindo a educação. A mudança no padrão de produção também produziu uma reorganização nas estruturas administrativas, substituindo o modelo burocrático de gestão por um modelo mais dinâmico e flexivel. Esse modelo, denominado de gerencialismo tem influenciado a gestão educacional, descentralizando os seus serviços e trazendo uma noção de maior transparência e responsabilidade para os gestores públicos. No entanto, também tem reforçado modelos de avaliação de desempenho, novas formas de controlar o orçamento, os serviços públicos, e estimulando o Estado a realizar parcerias, desobrigando-o de cumprir com suas funções no que se refere às políticas sociais.

Essas novas diretrizes passam a servir de parâmetros fundamentais, a partir dos quais os paises de acordo com as suas peculiaridades locais passaram a redesenhar as suas antigas estruturas administrativas com a finalidade de racionalizar os meios e buscar a eficiência e a produtividade dos serviços.

Na América Latina, mais especificamente no Brasil, a partir da década de 1990, esse novo modelo de administração pública passa a fazer parte da agenda política com as propostas de reformas do Estado a partir do governo de Fernando Henrique Cardoso. Nesse sentido, temáticas como descentralização, privatização e desregula- 
mentação se fizeram presentes nesse novo paradigma administrativo que, em maior ou menor escala, foram sendo implementadas como políticas públicas no país.

Esse novo paradigma perpassa por todas as áreas sociais, mas, especialmente no campo da educação, torna-se central e passa a ser sistematicamente orientado pelos organismos internacionais. Cabe destacar as atuações da UNESCO e do Banco Mundial, que, por meio de seminários, conferências, encontros e vários documentos, promoveram, a partir da década de 1990, o debate em torno desse novo paradigma de gestão pública contribuindo, de certa forma, para que os governos da região pudessem inclui-lo, gradativamente, em suas agendas políticas.

Nesse cenário, as proposições da Declaração da Conferência Internacional sobre Educação para Todos, realizada em Jomtien, 1990, se tornaram o marco das propostas de reformas educacionais. Consideramos que os compromissos assumidos pelos paises signatários dessa Conferência, pela sua amplitude, são praticamente inexequiveis, sob o ponto de vista da viabilidade econômica. Os países reconhecem as dificuldades em fazer cumprir as metas propostas diante da necessidade de um aporte financeiro bem superior ao empregado na educação.

Portanto, não é de se admirar que a América Latina ainda esteja longe de atender à sua população com serviços educacionais de boa qualidade, principalmente àquela população que não tem como pagar por esses serviços. Essa é uma constatação feita quando da reunião em Dakar (MARCO..., 2000).

Os estudos constatam que aconteceram avanços principalmente no campo da gestão educacional, no entanto, ainda há muito que se realizar para implantar uma gestão que, realmente, garanta a participação dos sujeitos no campo educacional. As estratégias adotadas como o empowerment e o accountability, que, teoricamente, permitiriam uma maior participação e o controle dos gastos públicos pela população e pelos colegiados, ainda está muito longe de se tornar uma realidade na maioria das escolas, uma vez que ainda se constata a existência de práticas centralizadoras de gestão no cotidiano das escolas no Brasil.

Fica evidenciado, dessa forma, que o modelo de gestão gerencial, orientado pelas agências internacionais, não tem conseguido superar o modelo de gestão burocrática que predominava nas escolas, como prognosticaram os apologistas do livre mercado. 0 que se constata é a transformação desta em uma burocracia flexivel, e principalmente, coerente com o novo modelo de produção.

Ressaltamos, ainda, que, apesar das críticas a esse modelo gerencial pela apropriação inadequada dos termos como participação, autonomia, descentralização, utilizadas, na lógica gerencial, como um processo necessário à racionalização dos recursos e não como mecanismos de gestão democrática, é possível a utilização dessas estraté- 
gias para a superação desse modelo e para a implantação de uma gestão participativa e com autonomia no interior das instituições escolares. Nesse sentido, o conselho escolar, a eleição de diretores, os conselhos de controle social e a elaboração do Projeto Político-Pedagógico são espaços de participação que devem ser ocupados por uma presença sempre ativa, eliminando a posição silenciosa, a omissão, ou a ausência da comunidade escolar dos processos de decisão no interior da escola.

Para alcançar esse objetivo, é imprescindivel que as políticas educativas se voltem para o fortalecimento da escola pública favorecendo uma maior igualdade e a construção de uma sociedade efetivamente democrática e equitativa. É importante compreender que um processo democrático e participativo pressupõe igualdade de condições, um nivelamento das diferenças sociais e de status, para que as pessoas possam participar em condições de igualdade. Isso não tem acontecido nos sistemas públicos de ensino nos quais a situação econômica dos participantes nos espaços colegiados é bastante desigual, fazendo com que aqueles detentores de mais renda e escolaridade acabem por ter mais voz no processo decisório.

0 fortalecimento da escola pública requer, portanto, a criação de uma cultura de participação para todos os seus segmentos e a melhoria das condições efetivas para que essa participação possa a vir se efetivar. Esse é o desafio que está posto para os educadores que acreditam na possibilidade da criação dos espaços democráticos como superação da nova lógica de mercado presente na atual política educacional.

\section{Referências}

ABRUCIO, F. L. Os avanços e os dilemas do modelo pós-burocrático: a reforma da administração pública à luz da experiência internacional recente. In: BRESSER PEREIRA, L. C.; SPINK, P. (Org.). Reforma do Estado e administração pública gerencial. 5. ed. Rio de Janeiro: FGV, 2003.

O impacto do modelo gerencial na administração pública: um breve estudo sobre a experiência internacional recente. Brasilia, DF, 1997. (Cadernos ENAP, n. 10).

ANTUNES, R. Os sentidos do trabalho: ensaio sobre a afirmação e a negação do trabalho. São Paulo: Boitempo, 2000.

BRAVERMAN, H. Trabalho e capital monopolista: a degradação do trabalho no século XX. 3. ed. Rio de janeiro: LTC, 1987.

BRESSER PEREIRA, L. C. Gestão do setor público: estratégia e estrutura para um novo Estado. In: BRESSER PEREIRA, L. C.; SPINK, P. (Org.). Reforma do Estado e administração pública gerencial. 2. ed. Rio de Janeiro: FGV, 1998. 
BRESSER PEREIRA, L. C. Gestão do setor público: estratégia e estrutura para um novo Estado. In: BRESSER PEREIRA, L. C.; SPINK, P. (Org.). Reforma do Estado e administração pública gerencial. 5. ed. Rio de Janeiro: FGV, 2003.

BORGES, A. Lições de reformas da gestão educacional: Brasil, EUA e Grã-Bretanha. Em Perspectiva, São Paulo, p. 78-79, 2004. Disponivel em < http//www.scielo.br>. Acesso em: 12 jun. 2007.

CABRAL NETO, A.; CASTRO, A. M. D. A. Gestão Educacional na América Latina: delineamentos e desafios para os sistemas de ensino. In: EYNG, A. M.; GISI, M. L.(Org.). Política e gestão da educação superior: desafios e perspectivas. Ijui: Unijui, 2007.

CABRAL NETO, A.; RODRIGUES, J. Reformas educacionais na América Latina: cenários, proposições e resultados. In: CABRAL NETO, A. et al. Pontos e contrapontos da politica educacional: uma leitura contextualizada de iniciativas governamentais. Brasília, DF, Liber Livro, 2007.

CAMPOS, A. M. Accountability: quando poderemos traduzi-la para o português?. Revista Brasileira de Administração Pública, Rio de Janeiro, p. 30-50, fev./abr. 1990.

CASTRO, A. M. D. A. Accountability: uma nova estratégia de controle da gestão escolar. In: CONFERÊNCIA INTERNACIONAL EDUCAÇÃO, GLOBALIZAÇÃO E CIDADANIA, 2008. Novas perspectivas da sociologia da educação: trabalhos apresentados... João Pessoa: UFPB, 2008. Disponivel em: <www.socieduca-inter.org/cd/ gt5/03.pdf>. Acesso em: 27 jun. 2008.

CLAD. La responsabilización ("accountability") en la nueva gestión pública latinoamericana. Buenos Aires, 2000. Disponible en:

$<$ http://unpan1.un.org/intradoc/groups/public/documents/CLAD/UNPAN000178.pdf >. Acceso en: 22 jan. 2007.

CLARKE, S. Crise do fordismo ou crise da social-democracia?. Lua Nova, São Paulo, n. 24, set. 1991.

DE ROSSI, V. L. Gestão do Projeto Político-Pedagógico: entre corações e mentes. São Paulo: Moderna, 2004.

DECLARAÇÃO Mundial Sobre Educação Para Todos: satisfação das necessidades básicas de Aprendizagens. Jomtien, Tailândia, 1990. Disponivel em: <www.unicef.org/brasil/jomtien.htl>. Acesso em: 13 fev. 2007. 
FONSECA, M. et. al (Org.). Escolas gerenciadas: planos de desenvolvimento e projetos político-pedagógicos em debates. Goiânia: UCG, 2004.

FRIEDMAN, M. Capitalismo e liberdade. São Paulo: Nova Cultural, 1985.

GAJARDO, M. Reformas educativas en América Latina: balance de una década. Chile: PREAL, 1999.

HADDAD, S.; SILVA, C. C. Educação para Todos: lição de casa malfeita. Observatório de Imprensa, São Paulo, 2000. Disponivel em: <http:// www.observatoriodaimprensa.com.br/artigos/pb05062000.htm>. Acesso em: 16 mar. 2011.

HARVEY, D. A condição pós-moderna. São Paulo: Loyola, 1993.

HAYEK, F. A. O caminho da servidão. Tradução Anna Maria Capovilla, José italo Stelle e Liane de Morais Ribeiro. 5. ed. Rio de Janeiro: Instituto Liberal, 1993.

MARCO de ação de Dakar. Educação para Todos: atingindo nossos compromissos coletivos. Dakar, Senegal, 2000. Disponivel em:

$<$ www.unesco.cl/medios/biblioteca/documentos/ept_dakar_accion_pgues.pdf $>$. Acesso em: 13 fev. 2007.

MARINI, C. Aspectos contemporâneos do debate sobre reforma da administração pública: a agenda herdada e as novas perspectivas. In: CONGRESSO INTERNACIONAL DEL CLAD SOBRE LA REFORMA DEL ESTADO Y DE LA REFORMA DA ADMINISTRACIÓN PÚBLICA, 8., Panamá, 2003. Anais... Panamá, 2003.

OLIVEIRA, D. Regulação das políticas educacionais na América Latina e suas conseqüências para os trabalhadores docentes. Educação e sociedade, Campinas, SP, v. 26, n. 92, out. 2005.

Regulação educativa na América Latina: repercussões sobre a identidade dos trabalhadores docentes. Educação em Revista, Belo Horizonte, n. 44, dez. 2006.

UNESCO. Balance de los 20 años del proyecto principal de educación en América Latina e el Caribe. Santiago, 2001.

Recebido em: 17/08/2009

Aceito para publicação em: 02/08/2010 